\title{
Classification of Schizophrenia Patients and Healthy Controls Using P100 Event-Related Potentials for Visual Processing
}

\author{
Shoji Tanaka ${ }^{a}$ Yosuke Maezawa $^{a}$ Eiji Kirino $^{b}$ \\ ${ }^{a}$ Department of Information and Communication Sciences, Sophia University, and ${ }^{\mathrm{b}}$ Department of Psychiatry, Juntendo \\ University School of Medicine, Tokyo, Japan
}

\section{Key Words}

Discriminant analysis - Event-related potentials .

Information processing $\cdot$ Schizophrenia

\begin{abstract}
The study of event-related potentials (ERPs) is capable of elucidating the abnormalities in brain network dynamics relevant to the information-processing deficits in schizophrenia patients. In contrast to P50 and P300 ERPs, however, the results of P100 ERP studies in schizophrenia patients are less consistent. We have previously reported that P100 amplitudes did not differ significantly between patients with schizophrenia and healthy subjects. This result raised a question as to whether P100 ERPs carry information on brain network dynamics in schizophrenia patients that is distinct from normal controls. To answer this question, in this study we performed discrimination analysis on the P100 data. The rate of correct classification of patients and controls was high (80-90\% depending on stimulus categories), indicating that patients have spatial patterns of P100 amplitudes that are distinguishable from those in healthy subjects. To further explore this possibility, we performed principal component analysis on the P100 data. For the patients, the first principal component represented global activity, the second component represented the reciprocal anterior-posterior activa-
\end{abstract}

tion, and the third component represented the hemispheric reciprocity in activity. The first and second components were similar to those of the control group; however, the third component in control subjects showed activation of the center versus anterior and posterior regions. This result is consistent with the notion of abnormalities in hemispheric asymmetries during the processing of sensory information in schizophrenia. In conclusion, this ERP study demonstrated that P100 amplitudes have information that can successfully classify patients and controls.

Copyright $\odot 2013$ S. Karger AG, Basel

\section{Introduction}

Neuroimaging is a promising method of assessing the normality of information processing in the brain because it permits the objective assessment of neural activation. Since the development of neuroimaging techniques such as event-related potentials (ERPs) and functional magnetic resonance imaging, a number of studies using these new techniques have detected abnormalities in patients with schizophrenia and other diseases. In many ERP studies, P50 and P300 ERPs have been robust indicators of disease $[1,2]$. These measures have assessed several aspects of information-processing deficits that have long

\begin{tabular}{ll}
\hline KARGER & $\begin{array}{l}\text { ( ) 2013 S. Karger AG, Basel } \\
\text { 0302-282X/13/0682-0071\$38.00/0 Openger }\end{array}$ \\
$\begin{array}{l}\text { E-Mail karger@karger.com } \\
\text { www.karger.com/nps }\end{array}$ & $\begin{array}{l}\text { This is an Open Access article licensed under the terms of the } \\
\text { Creative Commons Attribution-NonCommercial 3.0 Un- } \\
\text { ported license (CC BY-NC) (www.karger.com/OA-license), } \\
\text { applicable to the online version of the article only. Distribu- } \\
\text { tion permitted for non-commercial purposes only. }\end{array}$
\end{tabular}

Dr. Shoji Tanaka

Department of Information and Communication Sciences Sophia University

7-1 Kioicho, Chiyoda-ku, Tokyo 102-8554 (Japan)

E-Mail tanaka-s@sophia.ac.jp 
been proposed as having a central role in schizophrenia [3]. Along with prepulse inhibition, P50 suppression is reduced in patients with schizophrenia, which is suggestive of sensory gating deficits $[4,5]$. Interestingly, the prefrontal cortex has been suggested to be involved in the generation of P50 ERPs, which occurs at an early stage in sensory processing [6]. The auditory P300 ERP has been recorded in many studies using oddball tasks. The P300 amplitude increases as the probability of encountering an infrequent deviant stimulus decreases [7]. Patients with schizophrenia showed reduced amplitudes and prolonged latencies of P300 ERPs [1,2]. Recent studies using visual oddball tasks reported that patients with schizophrenia showed significant reductions of P300 amplitudes [8]. These diminished P300 ERPs, both auditory and visual, were recovered by the administration of an antipsychotic drug [9].

In contrast to P50 and P300, the studies of P100 ERPs in schizophrenia patients are less consistent. There are studies reporting reduced P100 amplitudes in patients with schizophrenia [10-12]; however, other studies have reported inconsistent results $[13,14]$ or found no differences [15-17]. The P100 amplitude correlated positively with both the Brief Psychiatric Rating Scale and the Scale for the Assessment of Negative Symptoms, exhibited variability across the electrodes, and was higher in patients than healthy controls at approximately $110 \mathrm{~ms}$ [13]. We recently recorded peaks at approximately $110 \mathrm{~ms}$ that were higher in patients than in healthy controls, although the differences did not reach significance [15]. The P100 latencies for a no-contour stimulus correlated with the cognitive subscales of the Positive and Negative Syndrome Scale [15], being consistent with cognitive impairment in patients $[15,18]$. On the other hand, the relationships with early sensory processing deficits have been obscure. Given that early-stage visual processing, which is typically in the range of less than $200 \mathrm{~ms}$ after stimulus onset, is also dysfunctional in schizophrenia patients [11, $12,19,20]$, P100 ERPs might reflect altered brain network dynamics that is relevant to early sensory processing deficits. To explore this possibility, we investigated P100 ERPs in the following two steps. First, we examined whether multielectrode P100 amplitudes could discriminate patients from healthy controls. Successful discrimination with the multielectrode P100 amplitudes would indicate that the ERP data contain information on the network dynamics of patients with schizophrenia that differs from healthy controls. Second, we attempted to extract principal components from the ERP data that might be relevant to the discrimination. The extracted
Table 1. Demographic and clinical characteristics of the participants

\begin{tabular}{|c|c|c|}
\hline & Patients & $\begin{array}{l}\text { Healthy } \\
\text { controls }\end{array}$ \\
\hline Age, years & $31.3 \pm 7.2$ & $31.8 \pm 5.0$ \\
\hline \multicolumn{3}{|l|}{ Sex, n } \\
\hline Male & 13 & 13 \\
\hline Female & 7 & 7 \\
\hline Age at onset, years & $21.4 \pm 6.0$ & \\
\hline Illness duration, years & $9.8 \pm 6.6$ & \\
\hline Total PANSS score & $72.3 \pm 18.6$ & \\
\hline \multicolumn{3}{|l|}{ Subtypes, $\mathrm{n}$} \\
\hline Disorganized & 7 & \\
\hline Paranoid & 4 & \\
\hline Catatonic & 2 & \\
\hline Residual & 6 & \\
\hline Unclassified & 1 & \\
\hline \multicolumn{3}{|l|}{ Amount of episodes including } \\
\hline that at the tests & $1.5 \pm 1.6$ & \\
\hline \multicolumn{3}{|l|}{ Antipsychotic medication, $\mathrm{n}$} \\
\hline Typical & 6 & \\
\hline Atypical & 14 & \\
\hline
\end{tabular}

Values are presented as mean \pm SD unless otherwise indicated. PANSS $=$ Positive and Negative Syndrome Scale.

component structure would clarify spatial characteristics of network dynamics reflecting information processing in the brain of patients as well as controls.

\section{Methods}

Participants

A total of 20 medicated, right-handed, schizophrenic patients ( 13 males) between the ages of 17 and 49 (mean \pm SD: $31.3 \pm$ 7.2) were recruited at the Juntendo Koshigaya Hospital in Saitama, Japan (table 1). The patients who participated in this study met the Diagnostic and Statistical Manual of Mental Disorders fourth edition (DSM-IV) criteria for schizophrenia and had relatively mild psychotic manifestations. The majority of the patients had intact social adjustments, either having an occupation or being a student, until the manifestation of psychotic episodes. The Positive and Negative Syndrome Scale [21] scores were recorded on the basis of a structured psychiatric interview and by a review of the medical charts of the patients. The ages at onset were $21.4 \pm 6.0$ and the durations of the disease were $9.8 \pm 6.6$ years. All patients were medicated with typical $(n=6)$ or atypical antipsychotic drugs $(n=$ 14). The patient and healthy control groups were matched for age, handedness and gender. The demographic and clinical characteristics of the participants are summarized in table 1. All patients were judged to be in good physical health on the basis of medical history, physical examination and laboratory measures. None of the subjects had a history of electroconvulsive shock treatment,
72

Neuropsychobiology 2013;68:71-78 DOI: $10.1159 / 000350962$
Tanaka/Maezawa/Kirino 


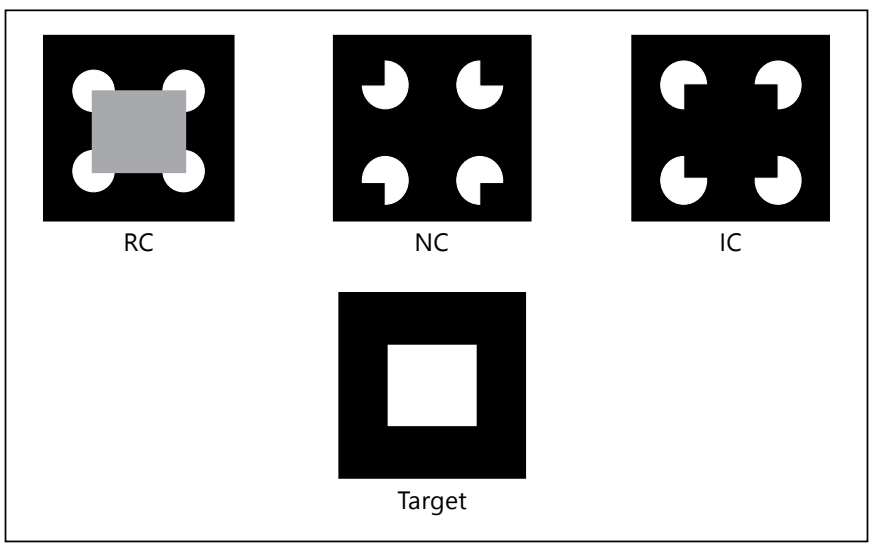

Fig. 1. Stimulus categories: Real contour (RC), no contour (NC) and illusory contour (IC) (Kanizsa's square).

alcohol or other drug abuse (DSM-IV criteria), addiction, or a neurologic illness affecting the central nervous system. After a complete description of the study, all subjects provided written informed consent to the protocol, which was approved by the Institutional Review Board of Juntendo University.

\section{Experimental Tasks and Procedures}

We used four stimulus categories: (1) real contour (RC) comprising a real square, filling the square with inducers; (2) no contour (NC) comprising four inducers positioned in a misangled manner such that no illusory contour was generated; (3) illusory contour (IC) comprising Kanizsa's square, and (4) a white square (the target; fig. 1). This set of stimulus categories was used in the previous study [15] to assess top-down and bottom-up visual information processing. This study, however, did not intend to assess such visual information flow. Instead, this study tried to characterize spatial distribution of P100 ERP amplitudes over electrodes that were evoked by the processing of these categories of visual stimuli. The stimulus duration was $250 \mathrm{~ms}$, and the onset-to-onset interval was 1,800$2,300 \mathrm{~ms}$. The stimuli were presented on a computer monitor that subtended a visual angle of $5.4 \times 5.4^{\circ}$. Each of the four stimulus categories was pseudorandomly distributed with equal probability over a single session. In each experiment, each stimulus category was presented 100 times. To evaluate the attention of subjects and the contamination of sleepiness, the subjects were required to respond to white squares. In contrast, the subjects were required to make no response to $\mathrm{RC}, \mathrm{NC}$ or IC to exclude the effects related to the button-press response, such as motor preparation. The subjects were instructed to avoid unnecessary eye movement and eye blinking during the session. After the ERP sessions, the subjects were asked how distinctly they recognized the illusory square in IC with a visual analog scale using a rating of $1-5$, where 5 is the best.

\section{Electroencephalogram Recording}

The electroencephalogram (EEG) was recorded using $\mathrm{Ag} / \mathrm{AgCl}$ disk electrodes placed at 19 sites (Fp1, Fp2, F7, F3, Fz, F4, F8, T3, $\mathrm{C} 3, \mathrm{Cz}, \mathrm{C} 4, \mathrm{~T} 4, \mathrm{~T} 5, \mathrm{P} 3, \mathrm{Pz}, \mathrm{P} 4, \mathrm{~T} 6, \mathrm{O} 1$ and $\mathrm{O} 2$ ) using the standard $10 / 20$ system. The recording electrodes were referenced to the nose. A bipolar electrode pair was placed above and over the outer canthus of the right eye to record the electrooculogram (EOG). The impedances of all electrodes were maintained below $5 \mathrm{k} \Omega$. The EEG data were analyzed using a SYNAFIT-REE2500 SynaViewer-R ES5003 (GE Marquette), EPLYZER II-R (Kissei Comtec), system. During the task, the EEG and EOG were continuously digitized at $500 \mathrm{~Hz}$ per channel and stored on a computer disk using an online filter of $0.1-100 \mathrm{~Hz}$. The EEG was filtered offline with a bandpass of $0.5-60 \mathrm{~Hz}$. The digital codes for each stimulus category were synchronized to the stimulus onsets and stored. EEG epochs of $850 \mathrm{~ms}$ duration ( 425 points; $100 \mathrm{~ms}$ prestimulus and $750 \mathrm{~ms}$ poststimulus) associated with each stimulus type were extracted from the continuous record. Artifact-free epochs were segregated according to the stimulus codes. The root mean square voltage of the EOG channel was computed to identify and discard the epochs associated with eye movements and blink artifacts. The raw EEG data from each epoch were inspected during the review on the monitor screen. The epochs contaminated by EOGs, blinks or muscle artifacts exceeding an artifact rejection threshold of $\pm 80 \mu \mathrm{V}$ at any electrode were omitted from the analysis. All single trial epochs were baseline corrected $(100 \mathrm{~ms})$ prior to the subsequent process and averaged for each subject. There was no significant difference in the amount of accepted sweeps between groups between the stimulus codes. The peak amplitudes of P100 were detected at around $100 \mathrm{~ms}$ (the mean \pm SD of the peak latencies for schizophrenia patients and healthy controls, respectively, were as follows: $122.1 \pm 23.3$ vs. $114.4 \pm 23.3 \mathrm{~ms}$ for RC, $116.8 \pm 25.1$ vs. $109.5 \pm 28.3 \mathrm{~ms}$ for NC and $116.3 \pm 27.5 \mathrm{vs} .111 .8 \pm 24.0 \mathrm{~ms}$ for IC).

\section{Discriminant Analysis}

Discriminant analysis attempts to predict group membership from a set of predictors [22]. In linear discriminant analysis, the discriminant function is defined by a linear combination of independent variables or predictors as follows:

$$
\mathrm{D}=\mathrm{a}_{1} \mathrm{X}_{1}+\ldots+\mathrm{a}_{\mathrm{p}} \mathrm{X}_{\mathrm{p}}
$$

where $\mathrm{D}$ is the discrimination function, $\mathrm{X}_{1}, \mathrm{X}_{2}, \ldots, \mathrm{X}_{\mathrm{p}}$ are the predictors, and $a_{1}, a_{2}, \ldots, a_{p}$ are the standardized discrimination function coefficients. In this study, the predictors are P100 amplitudes at the corresponding electrodes, and $p=19$, which is the number of electrodes. The discrimination function $\mathrm{D}$ was calculated for each group (patients and healthy controls) and for each stimulus category (RC, NC and IC). The mean of the discrimination function over the two groups for each stimulus category was zero because the predictors were standardized. If the score of the discrimination function for a subject was less than zero, the subject was classified as a patient with schizophrenia. The discriminant analysis was performed with SPSS Statistics for Windows, version 20 (IBM Corp., New York, N.Y., USA).

\section{Principal Component Analysis}

The P100 amplitude data for the three categories of stimuli were subjected to principal component analysis (PCA). From the data, the PCA extracted principal components, which had characteristic scalp distributions. The analysis was performed for the patient group and the control group separately, so that the analysis yielded different sets of principal components for the two groups. In each group, the principal components whose eigenvalues were greater than 1.0 were subjected to interpretation. The PCA was performed with R (the R Statistical Computing Environment). 


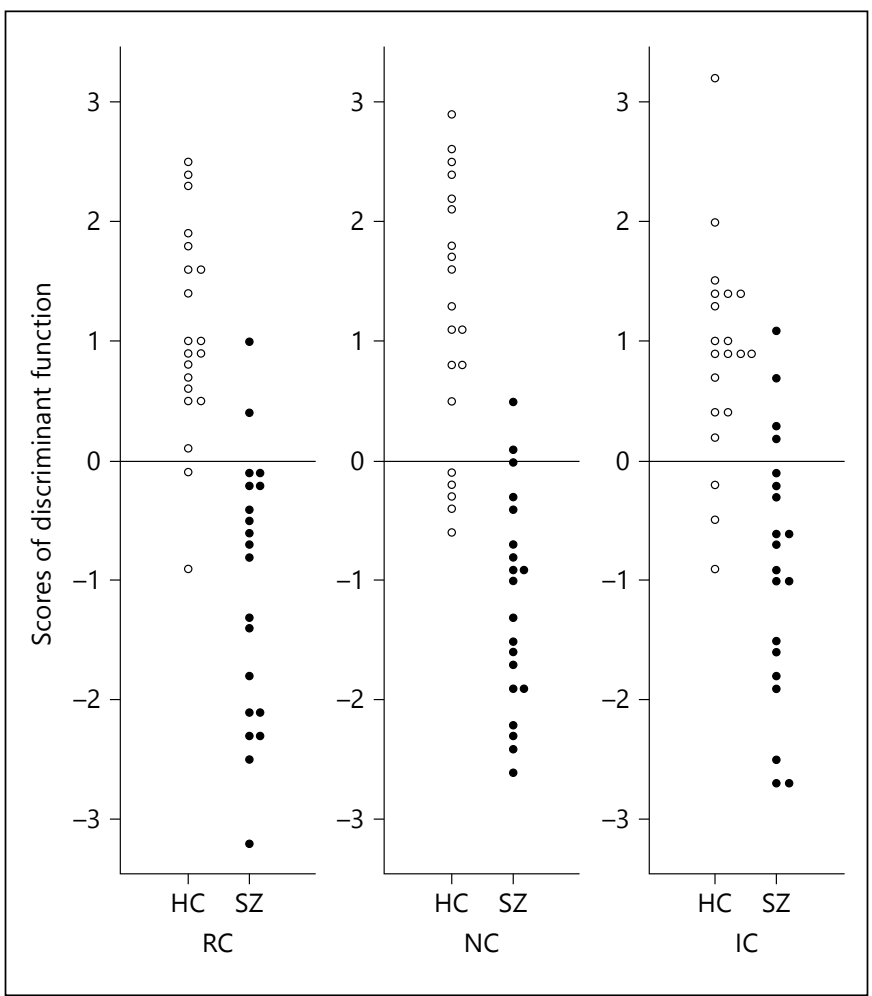

Fig. 2. Scatter plots of the scores of the discriminant function, defined by equation 1 in the text. Open circles: healthy controls, filled circles: patients. The discriminant analysis classified subjects with positive scores as healthy controls and subjects with negative scores as patients. Mean values of the scores of controls and patients were 1.06 and -1.06 , respectively $\left(\mathrm{p}=2.1 \times 10^{-8}\right)$ for $\mathrm{RC}, 1.19$ and $-1.19\left(\mathrm{p}=6.4 \times 10^{-9}\right)$ for $\mathrm{NC}$ and 0.89 and $-0.89(\mathrm{p}=2.1 \times$ $\left.10^{-6}\right)$ for IC.

\section{Results}

\section{Classification of Patients and Controls}

From the observed P100 amplitudes, which were the predictors of the discriminant function, given by equation 1 , the discriminant analysis estimated the scores for individual subjects, $\mathrm{D}$. The distributions of the scores for both groups of subjects are shown in figure 2. Negative values of the discriminant score classified the subjects as patients, while positive values classified the subjects as healthy controls. Although there was some overlapping, the distributions of the scores were well separated ( $\mathrm{p}<$ 0.00001 for RC, NC and IC). For the RC stimuli, 2 of the 20 healthy controls were mistakenly classified as patients, while 2 of the 20 patients were mistakenly classified as healthy controls. The rate of correct classification was $90.0 \%$. For the NC stimuli, 5 controls and 3 patients were mistakenly classified; the correct classification rate was $80.0 \%$. For the IC stimuli, 3 controls and 4 patients were mistakenly classified; the correct classification rate was $82.5 \%$.

\section{Principal Component Analysis}

If the P100 amplitudes differed significantly between the groups, the differences of the P100 amplitudes were the primary contributor to the discrimination of patients from controls. However, this was not the case in this study. One might consider that just an unweighted collection of P100 amplitudes at 19 electrodes would have increased the power of discrimination. This inference was denied because the average P100 amplitude over the electrodes did not differ between the groups $(\mathrm{p}=0.19$ for RC, 0.45 for NC and 0.27 for IC). On the contrary, the rather high discrimination rates indicate that patients had characteristic spatial patterns of the P100 amplitudes over the electrodes that were distinctive from those of healthy subjects. Then, to explore these patterns, we performed PCA on the P100 amplitudes. The PCA extracted the principal components (table 2). Among them, the first three components that had eigenvalues greater than 1.0 were retained (the eigenvalues for the first, second and third components were 9.60, 4.23 and 1.18, respectively). These three components explain $84.8 \%$ (for the patients) and $74.0 \%$ (for the controls) of total variance. All of the coefficients for the first principal component (PC1) had positive values (table 2), which indicates that this component represents global activity. This feature was the same in both patients and controls. However, although the coefficients for PC1 had the same sign, they were relatively higher in the frontocentral region than in the posterior region in the patient group. This feature was not seen in the control group. The coefficients for the second principal component (PC2) had negative values at the anterior electrodes and positive values at the posterior electrodes, while they were smaller with mixed signs at the central electrodes. Therefore, PC2 represents reciprocal anterior-posterior activation. In contrast to the first and second components, the third principal component (PC3) was essentially different between the groups. This component in the patient group showed the hemispheric reciprocity of activation, as the coefficients for PC3 had positive values in the left hemisphere and negative values in the right hemisphere. In contrast, PC3 in the control group did not show such hemispheric differences but rather showed the activation of the central versus the anterior and posterior regions. These results are visualized in figure 3. 
Table 2. Principal component coefficients or eigenvectors

\begin{tabular}{|c|c|c|c|c|c|c|c|}
\hline \multicolumn{4}{|c|}{ Patients with schizophrenia } & \multicolumn{4}{|c|}{ Healthy controls } \\
\hline & PC1 & PC2 & PC3 & & PC1 & PC2 & PC3 \\
\hline Fp1 & 0.211 & -0.257 & 0.075 & Fp1 & 0.202 & -0.308 & 0.395 \\
\hline Fp2 & 0.224 & -0.265 & -0.013 & $\mathrm{Fp} 2$ & 0.212 & -0.336 & 0.249 \\
\hline $\mathrm{Fz}$ & 0.269 & -0.172 & -0.194 & $\mathrm{Fz}$ & 0.244 & -0.166 & -0.209 \\
\hline F3 & 0.273 & -0.191 & 0.057 & F3 & 0.248 & -0.203 & 0.054 \\
\hline $\mathrm{F} 4$ & 0.270 & -0.188 & -0.159 & $\mathrm{~F} 4$ & 0.224 & -0.226 & -0.202 \\
\hline F7 & 0.256 & -0.211 & 0.195 & F7 & 0.254 & -0.241 & 0.111 \\
\hline F8 & 0.277 & -0.120 & -0.084 & F8 & 0.184 & -0.299 & 0.284 \\
\hline $\mathrm{Cz}$ & 0.288 & -0.018 & -0.143 & $\mathrm{Cz}$ & 0.257 & -0.022 & -0.326 \\
\hline $\mathrm{C} 3$ & 0.271 & 0.017 & 0.266 & $\mathrm{C} 3$ & 0.276 & 0.033 & -0.188 \\
\hline $\mathrm{C} 4$ & 0.280 & 0.042 & -0.284 & $\mathrm{C} 4$ & 0.245 & -0.038 & -0.353 \\
\hline T3 & 0.248 & -0.077 & 0.401 & $\mathrm{~T} 3$ & 0.200 & 0.062 & -0.158 \\
\hline $\mathrm{T} 4$ & 0.255 & 0.083 & -0.207 & $\mathrm{~T} 4$ & 0.232 & -0.101 & -0.114 \\
\hline T5 & 0.185 & 0.228 & 0.452 & T5 & 0.214 & 0.316 & 0.107 \\
\hline T6 & 0.175 & 0.324 & -0.156 & T6 & 0.220 & 0.159 & 0.125 \\
\hline $\mathrm{Pz}$ & 0.196 & 0.272 & -0.200 & $\mathrm{Pz}$ & 0.235 & 0.229 & -0.081 \\
\hline P3 & 0.163 & 0.311 & 0.318 & P3 & 0.250 & 0.276 & 0.054 \\
\hline $\mathrm{P} 4$ & 0.156 & 0.335 & -0.278 & $\mathrm{P} 4$ & 0.248 & 0.257 & -0.120 \\
\hline $\mathrm{O} 1$ & 0.121 & 0.343 & 0.227 & $\mathrm{O} 1$ & 0.196 & 0.298 & 0.392 \\
\hline $\mathrm{O} 2$ & 0.110 & 0.361 & -0.097 & $\mathrm{O} 2$ & 0.192 & 0.313 & 0.304 \\
\hline
\end{tabular}

In both groups, the first 3 components had eigenvalues greater than 1.0. These 3 components explain $84.8 \%$ (for the patients) and $74.0 \%$ (for the controls) of total variance.

\section{Discussion}

\section{Discrimination}

Because our previous analysis showed insignificant group differences in the P100 amplitudes [15], the first question we addressed was whether the P100 amplitude data could discriminate patients from healthy controls. The discriminant analysis provided the scores for the individual subjects, which differed significantly between the groups. As a result, the rates of successful classification of patients and healthy controls were $80-90 \%$ depending on the categories of visual stimuli. This result indicates that, although the ERP at each electrode did not carry sufficient information on the pathological dynamics of the brain of patients with schizophrenia, the assembly of information at individual electrodes increased the power of the classification. In fact, reducing the numbers of electrodes in the analysis decreased the discrimination rate monotonically. Note, however, that this increased power was not due to just the averaging of the amplitudes over the electrodes because the group differences in the averaged amplitudes did not reach significance. Instead, we inferred that there were spatial patterns in the distri- bution of ERP amplitudes that were specific to schizophrenia. To confirm this inference, we performed PCA on the ERPs. If this inference was correct, the PCA would extract components with spatial profiles that differed between patients and controls. If the PCA extracted only one significant component that had no specific spatial profile, so that the loadings on this component were somewhat homogeneously distributed over the electrodes, this inference was to be denied. The result of the PCA showed that three significant components were extracted. Two of the extracted components had obvious spatial profiles; one was anterior-posterior reciprocity and the other was left-right reciprocity. Therefore, we conclude that there were spatial patterns in the distribution of ERP amplitudes that could be specific to schizophrenia.

\section{Spatial Components of P100 Amplitudes}

The next question we addressed regarded the type of information the P100 ERPs carried that was utilized for the discrimination of patients from controls. The spatial components extracted by the PCA were the anterior-posterior and left-right reciprocity. The anterior-posterior 
Fig. 3. Spatial distribution of the coefficients of the extracted principal components. Red (color refers to online version only) indicates a positive value, while blue indicates a negative value of the coefficient at each electrode. Only the coefficients greater than 0.1 or less than -0.1 are colored. a-c Patients with schizophrenia. d-f Healthy controls. a, d The first principal component (PC1). b, e The second principal component (PC2). c, f The third principal component (PC3). Note that the PC1 coefficients are not colored (in $\mathbf{a}$ and $\mathbf{d}$ ) because all of them had values greater than 1.0 (see table 2).

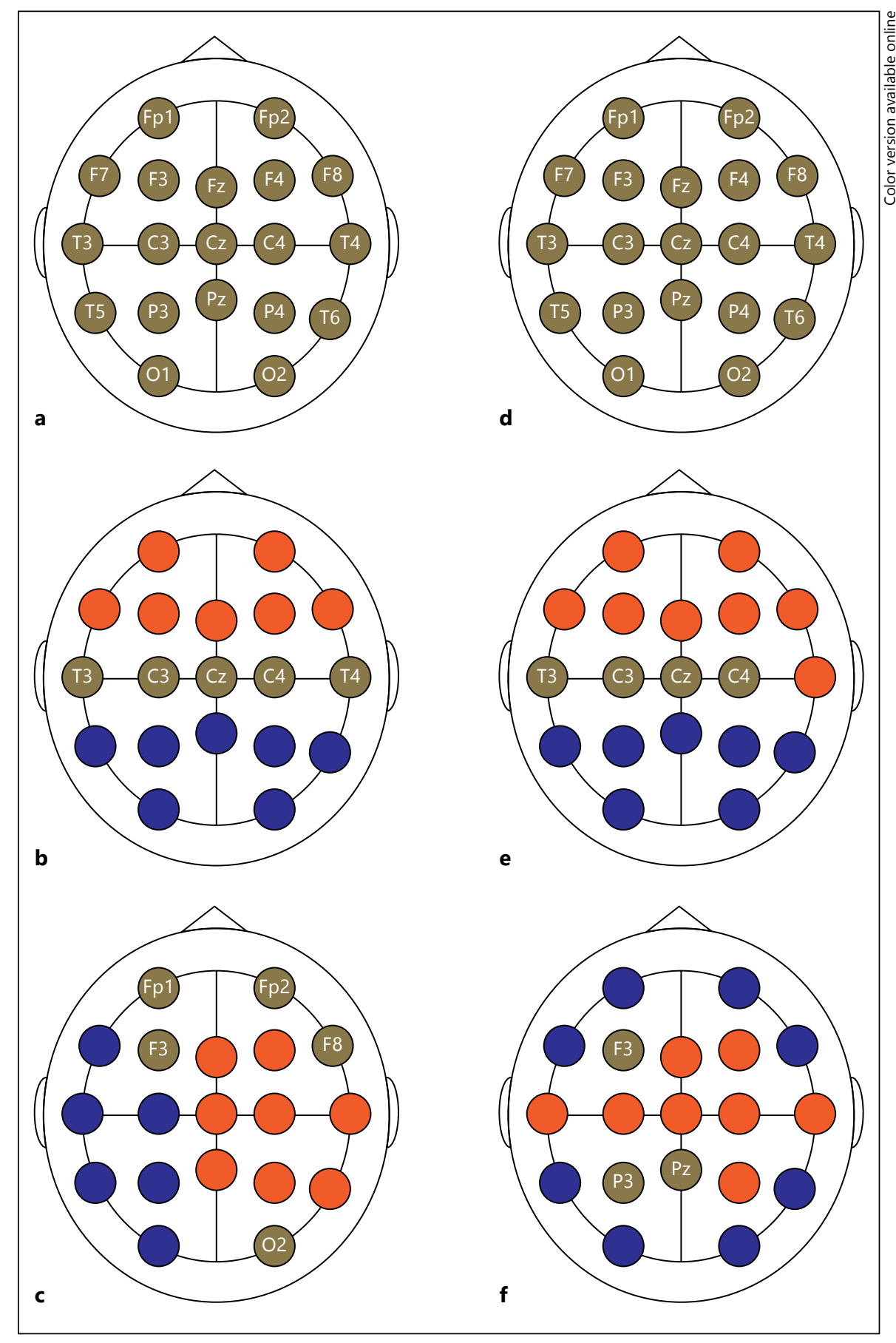

reciprocity might be relevant to hypofrontality or the abnormality of top-down processing in schizophrenia [23]. However, the PCA in this study extracted the anteriorposterior component in both groups, and the profiles of this component over the electrodes were similar. Given that the frontoparietal network plays a role in attentional control [24-26], this result may suggest that both groups utilized this network to perform the task. Similarly, it might be expected that both groups had the laterality component because sensory processing is asymmetrical even in healthy subjects $[27,28]$. However, the laterality component was extracted only from the patient group. 
This result suggests that, although hemispheric asymmetries of brain sensory information processing existed in both groups, the asymmetries were distorted further in patients with schizophrenia, being consistent with previous studies [29-31].

\section{Cortical Network Dynamics}

Although the difference at each electrode was subtle, the spatial components of P100 amplitudes as a whole had the power to discriminate patients from healthy subjects. The differences of the ERP spatial components between the groups would reflect the alterations of network dynamics in the patients, which would be relevant to the information-processing deficits in schizophrenia. A computational study suggested that the dynamics of the dorsolateral prefrontal cortex tends to be unstable under hypodopaminergic conditions and that processing speed becomes slower under the same conditions [32]. If topdown processing contributes to early visual processing, as suggested previously, the altered dynamics of the prefrontal cortex would influence the dynamics of the corti$\mathrm{cal}$ areas for visual information processing. This possibility was tested in previous studies $[15,18]$, in which the observed association between cognitive factor in the Positive and Negative Syndrome Scale scores and P100 latencies suggested the abnormality in top-down rather than bottom-up processing in patients with schizophrenia. To date, however, how schizophrenia influences network dynamics of the brain has not been elucidated. Therefore, for further exploration of distinctive network dynamics of schizophrenia and its relationship to psychopathology, a strategic approach integrating an ERP study with a computational study would be needed. Because all the patients in this study were medicated by either typical or atypical antipsychotic drugs, the medication effects on brain network dynamics are also to be examined. It is, nevertheless, meaningful that the analysis in this study showed successful classification of patients and healthy controls. In conclusion, multielectrode P100 ERPs, based on weighted combination of P100 amplitudes at individual electrodes, provides diagnostic classification power, which will be useful as a biomarker of the disease.

\section{Acknowledgments}

This research was supported by grants from Sophia University Human Informatics Research Center and the Research Support Foundation of the Juntendo Institute of Mental Health.

\section{Disclosure Statement}

The authors declare that the research was conducted in the absence of any commercial or financial relationships that could be construed as a potential conflict of interest.

\section{References}

$\checkmark 1$ Javitt DC, Spencer KM, Thaker GK, Winterer G, Hajos M: Neurophysiological biomarkers for drug development in schizophrenia. Nat Rev Drug Discov 2008;7:68-83.

2 Bramon E, Rabe-Hesketh S, Sham P, Murray RM, Frangou S: Meta-analysis of the P300 and P50 waveforms in schizophrenia. Schizophr Res 2004;70:315-329.

3 Braff DL: Information processing and attention dysfunctions in schizophrenia. Schizophr Bull 1993;19:233-259.

$\checkmark 4$ Korzyukov O, Pflieger ME, Wagner M, Bowyer SM, Rosburg T, Sundaresan K, Elger CE, Boutros NN: Generators of the intracranial P50 response in auditory sensory gating. Neuroimage 2007;35:814-826.

5 Brockhaus-Dumke A, Schultze-Lutter F, Mueller R, Tendolkar I, Bechdolf A, Pukrop R, Klosterkotter J, Ruhrmann S: Sensory gating in schizophrenia: P50 and N100 gating in antipsychotic-free subjects at risk, first-episode, and chronic patients. Biol Psychiatry 2008;64:376-384.

6 Weisser R, Weisbrod M, Roehrig M, Rupp A, Schroeder J, Scherg M: Is frontal lobe involved in the generation of auditory evoked P50? Neuroreport 2001;12:3303-3307.

7 Duncan CC, Barry RJ, Connolly JF, Fischer C, Michie PT, Näätänen R, Polich J, Reinvang I, Van Petten C: Event-related potentials in clinical research: guidelines for eliciting, recording, and quantifying mismatch negativity, P300, and N400. Clin Neurophysiol 2009; 120:1883-1908

-8 Ergen M, Marbach S, Brand A, Basar-Eroglu C, Demiralp T: P3 and delta band responses in visual oddball paradigm in schizophrenia. Neurosci Lett 2008;440:304-308.

-9 Park EJ, Han S-I, Jeon Y-W: Auditory and visual P300 reflecting cognitive improvement in patients with schizophrenia with quetiapine: a pilot study. Prog Neuropsychopharmacol Biol Psychiatry 2010;34:674-680.

10 Doniger GM, Foxe JJ, Murray MM, Higgins BA, Javitt DC: Impaired visual object recognition and dorsal/ventral stream interaction in schizophrenia. Arch Gen Psychiatry 2002;59: 1011-1020.

11 Foxe JJ, Doniger GM, Javitt DC: Early visual processing deficits in schizophrenia: impaired
P1 generation revealed by high-density electrical mapping. Neuroreport 2001;12:38153820.

12 Yeap S, Kelly SP, Sehatpour P, Magno E, Javitt DC, Garavan H, Thakore JH, Foxe JJ: Early visual sensory deficits as endophenotypes for schizophrenia: high-density electrical mapping in clinically unaffected first-degree relatives. Arch Gen Psychiatry 2006;63:11801188.

13 Yeap S, Kelly S, Sehatpour P, Magno E, Garavan $H$, Thakore J, Foxe J: Visual sensory processing deficits in schizophrenia and their relationship to disease state. Eur Arch Psychiatry Clin Neurosci 2008;258:305316.

14 Frodl-Bauch T, Gallinat J, Meisenzahl EM, Moller HJ, Hegerl U: P300 subcomponents reflect different aspects of psychopathology in schizophrenia. Biol Psychiatry 1999;45:116126.

15 Ikeda C, Kirino E, Inoue R, Arai H: Eventrelated potential study of illusory contour perception in schizophrenia. Neuropsychobiology 2011;64:231-238.
P100 Classification of Schizophrenia

Patients and Healthy Controls
Neuropsychobiology 2013;68:71-78 DOI: $10.1159 / 000350962$ 
16 Johnson SC, Lowery N, Kohler C, Turetsky BI: Global-local visual processing in schizophrenia: evidence for an early visual processing deficit. Biol Psychiatry 2005;58: 937-946.

17 Wynn JK, Lee J, Horan WP, Green MF: Using event-related potentials to explore stages of facial affect recognition deficits in schizophrenia. Schizophr Bull 2008;34:679-687.

18 Tanaka S, Maezawa Y, Ikeda C, Kirino E: Event-related potential study of early visual processing in schizophrenia patients: associations with cognitive symptoms. Abstr Soc Neurosci 2010;570:1

19 Butler PD, Schechter I, Zemon V, Schwartz SG, Greenstein VC, Gordon J, Schroeder CE, Javitt DC: Dysfunction of early-stage visual processing in schizophrenia. Am J Psychiatry 2001;158:1126-1133.

20 Campanella S, Montedoro C, Streel E, Verbanck P, Rosier V: Early visual components (p100, N170) are disrupted in chronic schizophrenic patients: an event-related potentials study. Clin Neurophysiol 2006;36:71-78.
21 Kay SR, Fiszbein A, Opler LA: The Positive and Negative Syndrome Scale (PANSS) for schizophrenia. Schizophr Bull 1987;13:261-276.

22 Tabachnick BG, Fidell LS: Using Multivariate Statistics, ed 5. Boston, Pearson, 2007.

23 Koychev I, El-Deredy W, Mukherjee T, Haenschel C, Deakin JF: Core dysfunction in schizophrenia: electrophysiology trait biomarkers. Acta Psychiatr Scand 2012;126:5971.

24 Coull JT, Frith CD, Frackowiak RS, Grasby PM: A fronto-parietal network for rapid visual information processing: a PET study of sustained attention and working memory. Neuropsychologia 1996;34:1085-1095.

25 Tanaka S: A prefronto-parietal network model with feedforward and feedback connections. Neurocomputing 2003;52-54:943-948.

26 Kastner S, Ungerleider LG: Mechanisms of visual attention in the human cortex. Annu Rev Neurosci 2000;23:315-341.

27 Hellige JB: Hemispheric asymmetry for visual information processing. Acta Neurobiol Exp (Wars) 1996;56:485-497.
28 Ritzl A, Marshall JC, Weiss PH, Zafiris O, Shah NJ, Zilles K, Fink GR: Functional anatomy and differential time courses of neural processing for explicit, inferred, and illusory contours: an event-related fMRI study. Neuroimage 2003;19:1567-1577.

29 Braus DF, Weber-Fahr W, Tost H, Ruf M, Henn FA: Sensory information processing in neuroleptic-naive first-episode schizophrenic patients: a functional magnetic resonance imaging study. Arch Gen Psychiatry 2002;59: 696-701.

30 Heckers S, Goff D, Weiss AP: Reversed hemispheric asymmetry during simple visual perception in schizophrenia. Psychiatry Res 2002; 116:25-32.

31 Connolly JF, Gruzelier JH, Manchanda R, Hirsch SR: Visual evoked potentials in schizophrenia. Intensity effects and hemispheric asymmetry. Br J Psychiatry 1983;142:152-155.

32 Tanaka S: Dopaminergic control of working memory and its relevance to schizophrenia: a circuit dynamics perspective. Neuroscience 2006;139:153-171. 